\title{
A repressão ao potencial criador
}

\author{
Eunice M. L. Sorlano de Alencar*
}

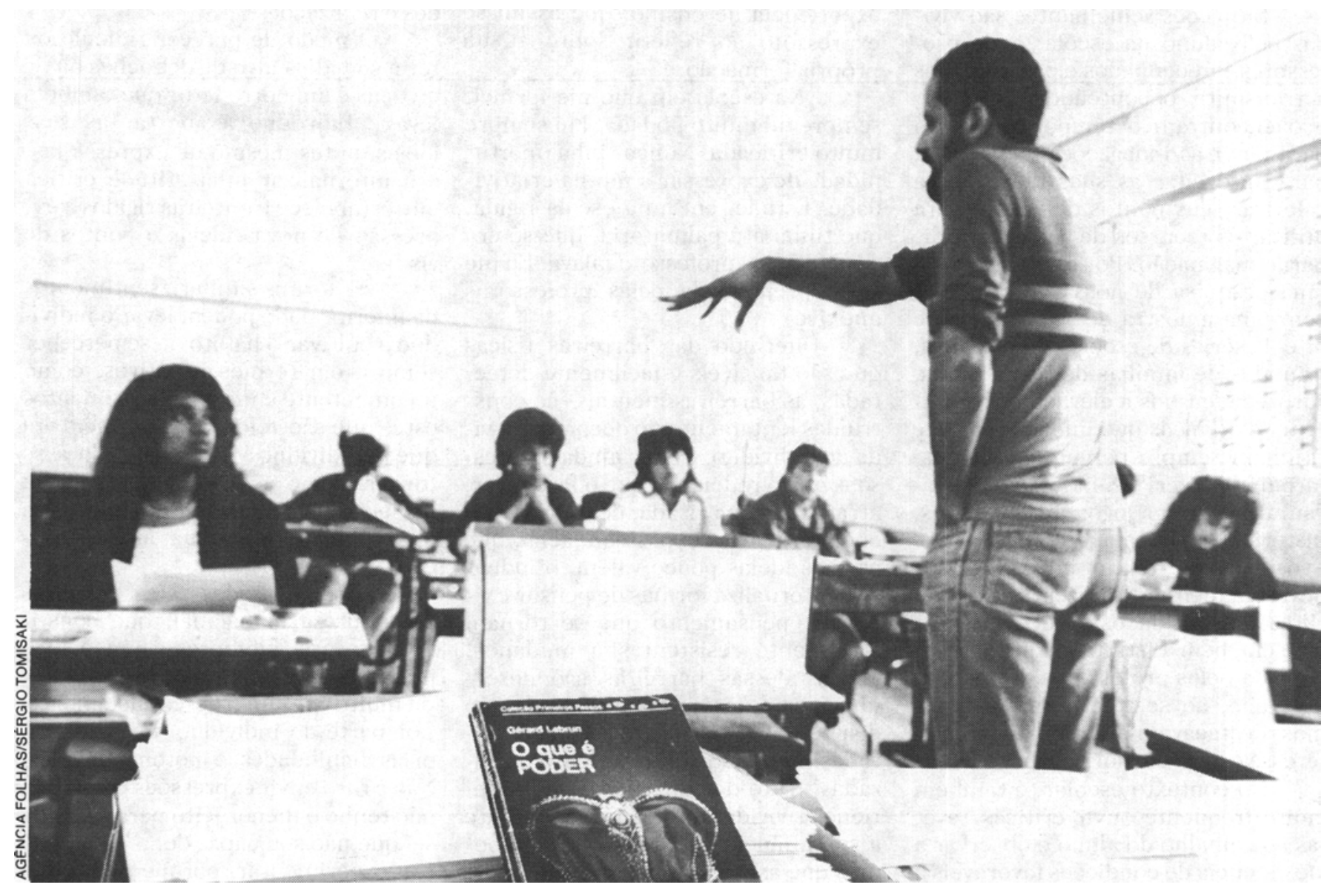

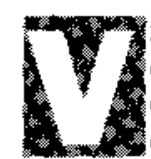

jvemos em uma sociedade que nos ensina, desde muito cedo, a controlar as nossas emoçōes, a resguardar a nossa euriosidade, a evitar situaçôes que poderiam redundar em sentimentos de perda ou de fracasso. Aprendemos tambèm, desde os nossos primeiros anos, a criticar as nossas idéias e a acreditar que o talento, que a inspiraçáo, que a criatividade sào o resul. tado de fatores sobre os quais temos pouco controle e que estariam presentes em apenas poucos individuos

- Professora do Instituto de Psicologia da Universidade de Brasilia. privilegiados. Aprendemos a nào explorar as nossas idéias e a bloquear a expressāo de tudo aquilo que poderia ser considerado ridiculo ou motivo de crítica.

Outras aprendizagens ocorrem também desde os primeiros anos, contribuindo para falsificar a nossa percepçảo do mundo e de nossas possibilidades. Este aspecto foi bem lembrado por Schiff (4), que assim se expressou: "Quem nào ouviu centenas de vezes: Nào toque nisso! Venha imediatamente! Que teimosia! A cada instante de sua existência, a criança é confrontada a proibiçōes, recomendaçōes, reprovaçōes, que tentam lhe fazer crer que ela seria incapaz de fazer algo por si só. Quando se tornc. adulta, esta velha eriança tenderá a agir com os jovens, do mesmo modo que agiram com ela".

Premidos tambem por uma ne. cessidade de ser aceitos, somos muitas vezes levados a anular as nossas idéias, a limitar as nossas experiências, a bloquear nosso crescimento. Este è um processo lento e gradual, que começa muito cedo na vida de cada eriança, e que sofre o impacto de situaçòes diversas ocorridas no seio da familia e da escola. Um exemplo ilustrativo de uma dessas situaçóes é a de um garoto que, a cada pergunta que fazia ao pai, recebia como resposta um encolher de ombros, ou um 
comentário do tipo "nào me amole", "me pergunte depois, porque agora estou ocupado", "deixe de lado essas idéias e vai brincar". A erianca aprende, desde muito cedo, que os comportamentos mais valorizados pelos seus pais, nào são comportamentos que levam à exploraçào,à descoberta e mesmo ao crescimento, mas antes, comportamentos que le. varu ao conformismo, à passividade, à estcreotipia.

Situaçòes semelhantes sāo vivi. das pelo aluno na escola, onde professores, preocupados e pressionados a transmitir o conteudo eurricular, nào encontram o tempo necessário para ouvir as indaǵaçōes da criança, para aproveitar as suas idéias, para valorizar seus pontos de vista e para utilizar os recursos de sua extraordinária imaginaçào. Por outro lado, em uma pesquisa de nossa autoria (2), com uma amostra de 140 alumos de $3^{a}$ e $4^{a}$ séries de escolas de periferia, oriundos de familias de baixa renda, surpreendeu-nos a elevada porcentagem de crianças que informaram que "tinham sempre perguntas que gos. tariam de fazer" (84\%), "que gostavam de inventar jogos, brincadeiras, histórias ou poemas" (91\%) e que "gostavam de tentar novas idèias e novas maneiras de fazer as coisas" $(90 \%)$. Estes dados forneciam uma imagem bem distinta daquela apresentada pelos professores desses alunos, que, ao se referirem aos mesmos, destacavam a sua apatia, desinteresse e falta de motivaçào.

No contexto escolar, é tambèm muito freqüente ouvir criticas severas ao trabalho do aluno e observar a inexistência de condiçóes favoráveis à expressào de suas idéias e individualidade. Uma situaciao observada pela autora, que ilustra o que costuma ocorrer em uma sala de aula, foi a de uma professora de $3^{a}$ série que, após solicitar aos alunos para desenhar uma paisagem, comentou cada um dos desenhos feitos em termos bas. tante negativos, mostrando os trabalhos realizados individualmente para toda a classe e expressando a sua insatisfaçào e critica diante de cada produto analisado.

Em nenhum momento refletiu esta professora sobre o impacto que poderia ter sobre a erianca o fato de ver o seu trabalho criticado diante de todos os colegas, ou ouvir uma avaliaçào altamente depreciativa de algo que foi feito com empenho e esforco.
As conseqüèncias adversas ao nivel do sentimentos de autodepreciaçāo, fracasso e vergonha também nảo foram consideradas.

Sâo situaçōes como esta que contribuem para a formaçào de barreiras internas à própria expressâo criativa e para uma visão limitada dos próprios recursos e habilidades. Elas permanecem vivas tia memória do individuo, como podemos observar em uma professora, com muitos anos de experiència de ensino, que assim se expressou, ao refletir sobre a sua própria formaça:

"Na escola em que me formei. sempre fui muito podada. Fui semprc muito eriticada. Nunca tinha oportu. nidade de expressar a minha criativi dade. Estudei em uma escola rigida, que tinha até palmatória, que só era certo o que a professora falava. Eu me sinto prejudicada pelas professoras que tive".

Diferindo das barreiras fisicas que sào tangiveis e facilmente detec. tadas, as barreiras mentais são cons. truidas lentamente no decorrer da vida do individuo. Com a ajuda das pes. soas que o rodeiam e que o fazem ver, através de uma risada, de um muchocho, ou de uma expressảo fácial, que as suas ideias pouco valem, $o$ indivi. duo internaliza formas de pensar e tipos de pensamento que se tornam fortemente resistentes à mudanca. Muitas dessas barreiras sāo deseo. nhecidas do próprio sujeito, que nào dispóe de recursos para lidar com atjtudes mentais profundamente enraizadas, fruto da educaçào e das experiências vividas notadamente durante a sua infancia. Por outro lado, sabemos que as correntes mais dificeis de romper são aquelas que trazemos dentro de nós mesmos.

Dentre as barreiras emocionais, que dificultam o aproveitamento de rossas possibilidades, salientam-se a apatia, a insegurança, o medo de parecer ridiculo, o medo do fracasso e os sentimentos de inferioridade.

A apatia se traduz por uma des. crença, indisposiçào ou desinteresse em se tentar aproveitar as proprias idéias ou mudar o curso de uma açáo. Fla se expressa no comportamento de uma pessoa que encerra a sua idèia, dizendo para si mesmo ou para outros "não adianta tentar, porque el sei que nāo vai dar certo" ou "nào vale a pena o esforço, porque eu sei que nào vai funcionar"

Tambèm a insegurança è outra barreira emocional, que faz com que o individuo nào leve avante uma idèia e a inibir a sua açào. Ela constitui a raiz do medo de fracassar, de cometer erros, de nâo ser bem-sucedido no processo de concretizar uma idéia nova ou levar avante o projeto. Estc c outro fator que pode ser observado com frequência, levando o individuo a lançar mano das mais diversas justiticativas para náo dar inicio a um novo projeto, explorar novas possibilidades e realizacoes.

O medo de parecer ridiculo ou ter a sua idéia alvo de deboches ou de criticas é um outro fator que também leva o individuo a ahortar as suas idéias, antes mesmo de expressá-las, e a internalizar uma atitude erítica que estabelece fronteiras rigidas à ex. pressào de novas idéias e pontos de vista.

De forma similar, sentimentos de inferioridade podem levar o individuo a cultivar o hábito de se perceber sempre em termos negativos, como incompetente e incapaz, sentimentos estes que sào reforcados no meio em que o individuo vive, levando-o a se tornar alheio a qualquer esforco ou projeto que poderia contribuir para uma mudança em sua autopercep. çāo.

A par de todas estas barreiras de natureza emocional, que consti. tuem forças inibidoras a um pensamento mais flexível e inovador, é ainda muito comum o desconhecimento, por parte do individuo, de suas próprias habilidades e potencialidades. Nảo é raro ouvir expressōes como "eu nào tenho o menor jeito para...", "eu sei que nāo sou capaz de...", "eu nào vou experimentar, porque nào tenho as habilidades necessárias". Estas expressôes refletem uma noçào firme e inahalável das próprias limitaçôes e que resistem a qualquer tentativa ou sugestào de mudança. O mais sério é que é comum tais afirmaçóes serem feitas por pessoas que tiveram pouca ou nenhuma experiência em uma de. terminada área a respeito da qual te. cem tais consideraçòs, sem qualquer fundamentacào na realidade, fruto apenas da pura imaǵinaçào. Entretanto, esta atitude mental consti. tui um dos determinantes mais pode. rosos do comportamento, limitando as àreas de atuaçào e de experimen. tação da pessoa.

Tais barreiras emocionais coe. xistem com outras da natureza cultu. ral, presentes no meio em que o indi- 
viduo vive. Em nossa sociedade predomina, por exemplo, a consideração da fantasia e da reflexào como perda de tempo, a resistència à mudança, a valorizacáa da lógica e do raciocinio em detrimento do sentimento e da intuiçà, a enfase exagerada na resposta correta, na soluçāo conhecida, no fato certo.

Por outro lado, nesta segunda metade do seculo vinte, muitos avancos foram observados a nivel de diterentes ciências como a Psicologia, questionando a visão tradicional do homem e de suas possibilidades de crescimento. Poder-se-ia lembrar aqui, por exemplo, o Movimento da Potencialidade Jumana, que, fundamentando-se em dados obtidos em pesquisas nas áreas de "biofeed. back", parapsicologia e processos alterados da consciência, têm chamado at atençào para o imenso potencial do ser humano, o qual tem sido utilizado de forma muitíssimo limitada, per. manecendo muitas capacidades ini bidas por falta de estimulo, de encorajamento, de ambiente favoravel a seu desenvolvimento.

De forma similar, os representantes da Psicologia Humanística tèm chamado a atençajo, entre outros as. pectos, para: a) - o potencial humano para desenvolver-se, para tornar-se, para auto-realizar-se; )-as diferencas individuais, ressaltando que os seres humanos tèm talentos diversos, que merecem ser explorados e que devem ter condiçōes para se desenvolver. Rollo May, um dos expoentes da Psicologia Humanistica, no livro de sua autoria, $A$ coragem de criar (3), ressalta, por exemplo, que nāo basta 0 impulso interno para a auto-realizaçāo: segundo ele, também importantes sảo as condiçỏes presentes na sociedade, a qual deve possibilitar à pessoa liberdade de escolha e açāo, de tal forma que possa explorar novas idéias, novas possibilidades, reconhecendo e estimulando o potencial criador de cada individuo. $O$ próprio titulo deste livro de Rollo May $-A$ coragem de criar - nos faz reportar ao fato de que vivemos em uma sociedade, por vezes, tào castradora, que é preciso, com freqüència, coragem pa. ra expor as próprias idéias e para oul sar novas propostas.

É necessário que os agentes socializadores reflitam sobre os seus papéis e sobre a extensāo em que estariam contribuindo para diminuir as possibilidades de erescimento da

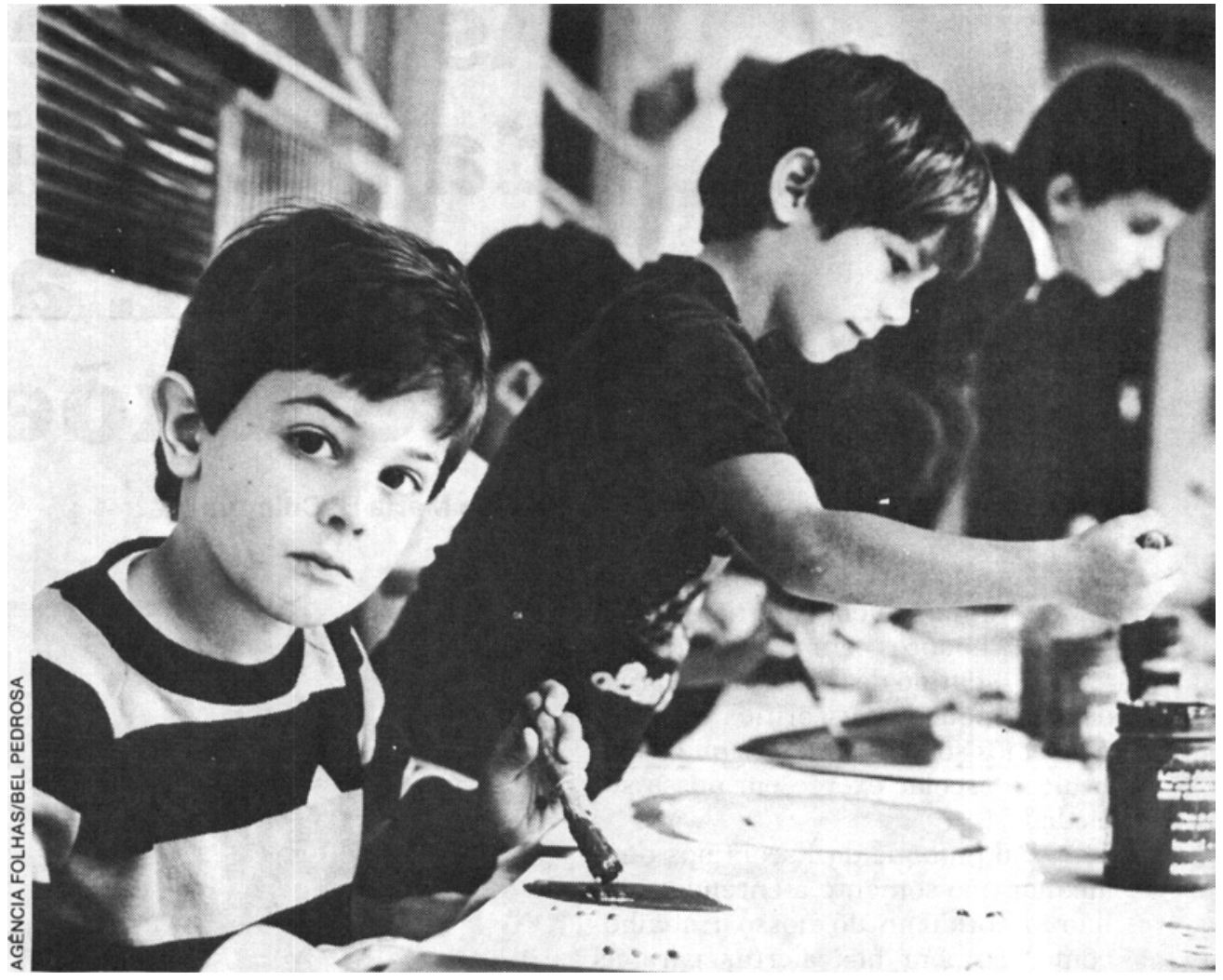

criança e do aluno, levando-os a erer que os seus recursos e possibilidades sejam muito menores do que real. mente são.

Para tal, muito eontribuiria o conhecimento advindo de algumas pesquisas na area de criatividade, as quais tèm descartado a visào da mes. ma como um dom presente em apenas alguns poucos individuos privilegiados, bem como a de que a criativi dade dependeria apenas de fatores intrapessoais, substimando-se a enorme contribuiçào da sociedade como um todo, para o processo eriativo. O papel das condiçōes ambien. tais foi destacado, entre outros, por Stein (5) que assim se expressou:

"Estimular a criatividade envolve nào apenas estimular o individuo, mas tambem afetar o seu ambiente social, e as pessoas que nele vivem. Se aqueles que circundam o individuo nào valorizam a criatividade, nào oferecem o ambiente de apoio necessário, nào aceitam o trabalho criativo quando este é apresentado, entào é possivel que os esforços cria tivos do individuo encontrem obstáculos sérios, senảo intransponiveis".

$\mathrm{O}$ que as pesquisas têm indiea. do também é que todo ser humano apresenta um certo grau de habilida. des criativas, que podem ser desen. volvidas e aprimoradas através da prática e do treino. Dados obtidos em pesquisas com individuos altamente criativos sugerem ainda que a criaçào nào é produto apenas de um lampejo de inspiração: a preparaçào do inndividuo, sua disciplina, dedicaçào, es forço consciente, trabalho prolonga. do, sào pré-requisitos importantes para a produçào criativa (Nota A) (1). Cabe a cada um de nós contri. buir para a existência de condiçòes mais adequadas para a expansào do talento e da criatividade e para uma visāo mais otimista dos recursos e possibilidades de cada individuo.

A - Para ayueles interessados no processo criador, sugito a leitura de Alencar( 1 .

1. AlENCAR E.M.L.S. - Pstcologia da Criatio dade. Porto Alegre, Artes Médiuas, 1986.

2.ALENCAR E.M.L.S.,FLEITH. D.S. SHIMABUKURO. L. A. \& NOBRE M.A. (no preto) Ffeitos de um programa de t reinamento de erjativjdade para professores do ensino de $1^{\circ}$ grau nas habilidades de pensamento eriativo do aluno. inte. ramerican Joumal of $P$ sychologn

MAY, R. A Coragem de Criar. Rio da lane ro, Nova Fronteira, 19\$2

4. SCHIFF, M. - L'Intelligence Grspillee. Ine galite Sociale, Injustice Sowlaire. Paris, Edj. tions du Sevil, 1982

5. STEIN M. I -Srimulating Creutivicy. Irulividual/Procedures. New York, Academic l'ress. 1974 